\title{
Selective M1 macrophage polarization in granuloma- positive and granuloma-negative Crohn's disease, in comparison to intestinal tuberculosis
}

\author{
Prasenjit Das ${ }^{1}$, Ritika Rampal ${ }^{2}$, Sonakshi Udinia ${ }^{3}$, Tarun Kumar ${ }^{1}$, Sucharita Pilli ${ }^{2}$, Nahid Wari ${ }^{2}$, Imtiaz Khan \\ Ahmed $^{2}$, Saurabh Kedia ${ }^{2}$, Siddhartha Datta Gupta ${ }^{1}$, Dhiraj Kumar ${ }^{3}$, Vineet Ahuja ${ }^{2}$ \\ Departments of ${ }^{1}$ Pathology and ${ }^{2}$ Gastroenterology and Human Nutritions, All India Institute of Medical Sciences, New Delhi, ${ }^{3}$ Cellular \\ Immunology Group, International Centre for Genetic Engineering and Biotechnology, New Delhi, India
}

Background/Aims: Classical M1 macrophage activation exhibits an inflammatory phenotype while alternative M2 macrophage activation exhibits an anti-inflammatory phenotype. We aimed to determine whether there are discriminant patterns of macrophage polarization in Crohn's disease (CD) and intestinal tuberculosis (iTB). Methods: Colonic mucosal biopsies from 29 patients with iTB, 50 with CD, and 19 controls were examined. Dual colored immunohistochemistry was performed for iNOS/CD68 (an $\mathrm{M}_{\varphi}$ marker) and CD163/CD68 (an $\mathrm{M} 2_{\varphi}$ marker), and the ratio of $\mathrm{M}_{\varphi}$ to $\mathrm{M} 2_{\varphi}$ was assessed. To establish the innate nature of macrophage polarization, we analyzed the extent of mitochondrial depolarization, a key marker of inflammatory responses, in monocyte-derived macrophages obtained from CD and iTB patients, following interferon- $\gamma$ treatment. Results: $\mathrm{M}_{\varphi}$ polarization was more prominent in CD biopsies $(P=0.002)$ than in iTB $(P=0.2)$ and control biopsies. In granuloma-positive biopsies, including those in $\mathrm{CD}, \mathrm{Ml}_{\varphi}$ predominance was significant $(P=0.001)$. In iTB, the densities of $\mathrm{Ml}_{\varphi}$ did not differ between granuloma-positive and granuloma-negative biopsies $(P=0.1)$. Interestingly, higher $\mathrm{Ml}_{\varphi}$ polarization in CD biopsies correlated with high inflammatory response exhibited by peripheral blood-derived monocytes from these patients. Conclusions: Proinflammatory $\mathrm{Ml}_{\varphi}$ polarization was more common in colonic mucosa of CD patients, especially in the presence of mucosal granulomas. Further characterization of the innate immune system could help in clarifying the pathology of iTB and CD. (Intest Res 2018;16:426-435)

Key Words: Crohn disease; Tuberculosis; Macrophage; M1 macrophage; M2 macrophage

\section{INTRODUCTION}

Crohn's disease (CD) is a consequence of aberrant im-

Received December 3, 2017. Revised March 15, 2018.

Accepted March 17, 2018.

Correspondence to Vineet Ahuja, Department of Gastroenterology, All India Institute of Medical Sciences, Room No. 3093, Third Floor, Teaching Block, New Delhi 110029, India. Tel: +91-11-26593300, Fax: +91-9810707170,

E-mail: vineet.aiims@gmail.com

Co-Correspondence to Dhiraj Kumar, Cellular Immunology Group,

International Centre for Genetic Engineering and Biotechnology, Aruna Asaf Ali Marg, New Delhi 110067, India. Tel: +91-9811263541, Fax: +91-1126742316, E-mail: dhiraj@icgeb.res.in mune response to environmental factors and gut microbiome, in genetically predisposed individuals. Intestinal tuberculosis (iTB) is an infectious disease caused by $\mathrm{Myco}$ bacterium tuberculosis. Despite their diverse etiologies, it is intriguing that their clinical presentation can be remarkably similar. ${ }^{1}$ Both the entities present with chronic intestinal inflammation as ulcero-constrictive intestinal disease. As CD is being increasingly seen in TB endemic areas, differentiating between the two can be a perplexing problem for the treating clinicians. ${ }^{2,3}$ Interestingly, granulomas in intestinal tissue are seen both in CD as well as iTB. ${ }^{1}$ Another intrigu-

\footnotetext{
(c) Copyright 2018. Korean Association for the Study of Intestinal Diseases. All rights reserved.

This is an Open Access article distributed under the terms of the Creative Commons Attribution Non-Commercial License (http://creativecommons.org/licenses/by-nc/4.0)

which permits unrestricted non-commercial use, distribution, and reproduction in any medium, provided the original work is properly cited.
} 
ing aspect is that mucosal epithelioid granulomas is among the histological parameters often reported to determine the clinical severity in CD. Patients with granulomas in CD hves been shown to have more clinical severity, recurrences, frequent fistula formation and postsurgical complications than in granuloma-negative $\mathrm{CD}^{4,5}$

Innate as well as adaptive immune responses play an important role in pathogenesis of CD as well as iTB. Over the last decade, it has been seen that the influence of innate immune response is possibly more as compared to adaptive immune response. ${ }^{6-10}$ Reciprocal interactions between macrophages and activated T-cells trigger adaptive immune responses and cytokines released by both the macrophages and the activated T-cells, further modulate each other. Gradually, the concept of this reciprocal activation between macrophages and T-cells has expanded and it has been seen that the interferon $\gamma$ (IFN- $\gamma$ ) released by type 1 T helper (Th1) cells and interleukin 4 (IL-4) released by the Th2 cells, activates 2 specific types of macrophage populations, the $\mathrm{Ml}_{\varphi}$ and $\mathrm{M} 2{ }_{\varphi}$, respectively. ${ }^{11-16}$ Mantovani and colleagues gave a clear concept regarding the stimulators and effects of $\mathrm{Ml}_{\varphi}$ (IFN- $\gamma$ combined with lipopolysaccharide [LPS] or tumor necrosis factor [TNF]) and M2 (IL-4 [M2a]; IL-10 and GCs $[\mathrm{M} 2 \mathrm{c}]) .{ }^{17}$ On the other hand, macrophage subtype responsible for immune regulation, stimulated by Fc receptors and immune complexes, were termed as $\mathrm{M} 2 \mathrm{~b}_{\varphi}$ by Moser and Murphy. ${ }^{10}$ Granulocyte-macrophage colony stimulating factor (GM-CSF) and macrophage colony stimulation factors (M-CSF) were identified as independent activators of M1 and $\mathrm{M} 2{ }_{\varphi}{ }^{18,19}$ Recently, we showed that classical activation of macrophages using IFN- $\gamma$ alone or in combination with LPS results is increased mitochondrial depolarization, lower autophagy and increased cellular reactive oxygen species leading to activation of inflammasome pathway. ${ }^{20}$ This allowed us to envisage an intriguing hypothesis to test whether macrophages from CD patients could respond more aggressively to a common inflammatory stimulus as against those from iTB patients.

As, both CD and iTB show histological presence of mucosal lymphomononuclear cells, along with macrophages, polymorphs and epithelioid cell granulomas in a sub-set, we intended to characterize the mucosal $\mathrm{M} 1_{\varphi}$ and $\mathrm{M} 2_{\varphi}$ polarization in them. Keeping in mind, that histologically presence of epithelioid cell granuloma in CD, may be an indicator of clinical disease severity, we included cases of both granuloma-positive and granuloma-negative $\mathrm{CD}$, along with iTB and control intestinal tissue, and compared the pattern of ${ }_{\varphi}$ polarization pattern among these clinical groups.

\section{METHODS}

\section{Patients and Controls}

Intestinal biopsies from 29 patients with treatment naïve iTB (19 are granulomas-positive), 50 patients with CD (8 are microscopic granuloma positive) and 19 controls (colonic mucosal biopsies from patients undergoing sigmoidoscopy for suspected hemorrhoidal bleed) were included. All samples were mucosal biopsies taken during colonoscopy/ sigmoidoscopy at the index visit.

\section{Definitions}

\section{1) Diagnosis of CD}

The diagnosis of CD was made on the basis of the European Crohn's and Colitis Organisation guidelines, with a combination of clinical, endoscopic and histological features. ${ }^{21}$

Ethical clearance was obtained from the Institutional Ethics Committee for all experiments on archival human biopsy samples (IESC/T-22/2/03/2015 \& for extension project IEC$304 / 2 / 06 / 2017$ ). Informed consent was taken from all patients before taking biopsies for diagnostic purposes as per our routine protocol.

\section{2) Diagnosis of iTB}

The diagnosis of iTB was made in an appropriate clinical setting with the demonstration of necrotizing granulomas on histopathology or demonstration of AFB on histopathology or culture of intestinal tissue. ${ }^{22}$

\section{3) Indeterminate Cases}

In patients who did not fulfil the above definitions, therapeutic trial with antitubercular treatment (ATT) was given. Diagnosis of iTB was made if patient had clinical and endoscopic response to ATT, and diagnosis of CD was made if the patient showed no response, worsened or worsened after initial improvement with standard ATT and subsequently showed a clinical and/or endoscopic response to oral steroids/CD specific therapy. ${ }^{3}$

Histological examination was performed independently by 2 experienced pathologists, blinded about the detail of cases and the findings were finally corroborated.

\section{Immunohistochemical Staining}

Formalin fixed paraffin embedded blocks were retrieved and $4 \mu \mathrm{m}$ thick sections were cut and were processed for 
immunohistochemical (IHC) stains as per the standard protocol. Dual color IHC staining was performed for the following combinations: rabbit polyclonal anti-human antibody against iNOS (Abcam, Cambridge, UK; 1:400)/goat antiCD68 (Abcam; 1:400) as a marker of M1 macrophages, and mouse monoclonal anti-human Ab against CD163 (Abcam; 1:400)/goat anti-CD68 (Abcam; 1:400), as marker of M2 macrophages were used. Anti-rabbit/mouse alkaline phosphatase labeled secondary antibody (Spring Bio, Pleasanton, CA, USA) and peroxidase labeled universal secondary antibody (Spring Bio) were used for detection, using neutral red and di-amino benzidine (DAB) as substrates, respectively. The iNOS/CD68 and CD163/CD68 ratio were divided into 4 groups: $0,<1,1-2$ and $>2$ for the purpose of comparison. The percentages of M1 and M2 positive macrophages were assessed, out of the total CD68 positive macrophages in tissue sections and compared amongst the biopsies of iTB, CD and in controls.

\section{In Vitro Culture of Macrophages for Validation}

\section{1) Isolation of PBMCs from Blood}

Blood collected in the heparinized tube was diluted 1:1 with Dulbecco's phosphate-buffered saline (DPBS) and layered onto $15 \mathrm{~mL}$ of Histo-paque solution. After density gradient separation ( $1800 \mathrm{rpm}, 30$ minutes), a layer of peripheral blood mononuclear cells (PBMCs) was collected carefully. The PBMCs were washed twice with DPBS (1800 rpm, 10 minutes) and the cells were counted using hemocytometer. Calculated number of cells were panned for 3.5 hours on the adherent surface without any serum.

\section{2) Maintenance and Differentiation of Isolated PBMCs}

After panning, cells were washed twice with DPBS. The Roswell Park Memorial Institute (RPMI) media with serum $(10 \%)$ and M-CSF $(50 \mathrm{ng} / \mathrm{mL})$ was added and incubated at $37^{\circ} \mathrm{C}$, with $5 \% \mathrm{CO}_{2}$. Cells were maintained in a tissue culture flask. Media change was given on the second day.

\section{3) Activation of Monocyte-Derived Macrophages (MDM)}

On the 6th day, the medium was discarded and the cells were washed with incomplete medium to remove traces of serum. The cells were detached using trypsinization. Following this, $0.3 \mathrm{~mL}$ of $0.25 \%$ trypsin solution was added to the cells and incubation was done for $\sim 10$ minutes in incubator (note: constant monitoring is important here to avoid over trypsinization of cells). Complete RPMI medium was added to the flask and the cells were flushed in order to detach the loosely adhering ones as well. The cell suspension was collected and centrifuged at $1800 \mathrm{rpm}$ for 10 minutes. The resultant cell pellet was suspended in $500 \mu \mathrm{L}$ of incomplete medium and cell counting was done. The cells were seeded in a 24 well plate at a density of 0.1 to 0.075 million cells per $\mathrm{mL}$ well. Two sets of conditions were applied: (1) untreated cells- where cells were maintained in complete medium and (2) IFN- $\gamma$ treated (RPMI added at $100 \mathrm{U} / \mathrm{mL}$ ) cells. Treatment was given for 24 hours.

\section{4) JC-1 Staining of Treated Macrophages}

The macrophages (supernatants removed in above section) were trypsinized and suspended in $500 \mu \mathrm{L}$ phenol free RPMI with $10 \%$ fetal calf serum and were scraped. These cells were then collected in fresh Eppendorf tubes. The sample sets made were: unstained untreated, untreated JC-1 stained and IFN- $\gamma$ treated JC- 1 stained. Cell suspensions were centrifuged at $1800 \mathrm{rpm}$ for 10 minutes. The supernatant was discarded. These cells were re-suspended in $200 \mu \mathrm{L}$ of phenol free RPMI containing JC-1 stain $(2 \mu \mathrm{M})$. The cells were vortexed and incubated at $37^{\circ} \mathrm{C}, 5 \% \mathrm{CO}_{2}$ for 30 minutes. The cells were centrifuged at $1800 \mathrm{rpm}$ for 10 minutes. The supernatant was discarded. The cells were re-suspended in $200 \mu \mathrm{L}$ of DPBS and proceed for flow cytometry.

\section{Statistical Analysis}

Data analysis was done by SAS version 9.2 software (SAS institute Inc., Cary, NC, USA) and appropriate statistical methods were applied for comparison among groups.

\section{RESULT}

\section{Clinical Characteristics}

Mean age \pm SD of patients with CD was $36.3 \pm 12.5$ years, those with iTB was $32.5 \pm 12.0$ years and in controls was 29.6 \pm 9.2 years. Two-thirds of both the diseases were mostly noted in the ileo-caecal junction, than in other parts of intestine. While $30 \%$ to $40 \%$ of granuloma-negative CD and iTB showed stricture, penetrating disease was seen in $7 \%$ of $\mathrm{CD}$. On the other hand, $50 \%$ and $47 \%$ of granuloma-positive CD and iTB had stricture, and penetrating disease was noted in $5 \%$ of granuloma-positive iTB. All patients of iTB were treatment naïve and biopsies were taken, when anti tubercular therapy was yet to be started. In total $42.8 \%$ of granulomanegative $\mathrm{CD}$ and $62.5 \%$ granuloma-positive $\mathrm{CD}$ got steroid therapy (Table 1). 
Table 1. Clinical and Histological Findings in Our Cohort $(n=79)$

\begin{tabular}{|c|c|c|c|c|}
\hline & \multicolumn{2}{|c|}{ Granuloma } & \multicolumn{2}{|c|}{ Non-granuloma } \\
\hline & iTB $(n=19)$ & $C D(n=8)$ & iTB $(n=10)$ & $C D(n=42)$ \\
\hline Age (yr) & $29.5 \pm 9.6$ & $29.75 \pm 6.7$ & $42.9 \pm 12.0$ & $36.4 \pm 13.2$ \\
\hline \multicolumn{5}{|l|}{ Age at diagnosis (yr) } \\
\hline$<16$ & $2(10.5)$ & 0 & 0 & $2(4.8)$ \\
\hline $17-40$ & 15 (78.9) & 7 (87.5) & $6(60.0)$ & $23(54.8)$ \\
\hline$>40$ & $2(10.5)$ & $1(12.5)$ & $4(40.0)$ & $17(40.5)$ \\
\hline \multicolumn{5}{|l|}{$\operatorname{Sex}$} \\
\hline Male & $10(52.6)$ & $4(50.0)$ & $6(60.0)$ & $27(64.3)$ \\
\hline Female & $9(47.3)$ & $4(50.0)$ & $4(40.0)$ & $15(35.7)$ \\
\hline Duration of the disease (mo) & $29.6 \pm 25.4$ & $48.6 \pm 44.5$ & $11 \pm 12.7$ & $58.4 \pm 73.1$ \\
\hline \multicolumn{5}{|l|}{ Behavior of the disease (Montreal classification) } \\
\hline Non-stricturing (B1) & $9(47.3)$ & $4(50.0)$ & $6(60.0)$ & $26(61.9)$ \\
\hline Stricturing (B2) & $9(47.3)$ & $4(50.0)$ & $4(40.0)$ & $13(30.9)$ \\
\hline Penetrating (B3) & $1(5.2)$ & 0 & 0 & $3(7.1)$ \\
\hline Perianal disease (P) & 0 & 0 & 0 & 0 \\
\hline \multicolumn{5}{|l|}{ Location of disease } \\
\hline Ileal (L1) & $6(31.5)$ & $2(25.0)$ & $2(20.0)$ & $12(28.5)$ \\
\hline Colonic (L2) & $5(26.3)$ & $3(37.5)$ & $2(20.0)$ & $13(30.9)$ \\
\hline Ileocolonic (L3) & 7 (36.8) & $3(37.5)$ & $6(60.0)$ & $13(30.9)$ \\
\hline Isolated upper digestive (L4) & $1(5.2)$ & 0 & 0 & $1(2.4)$ \\
\hline $\mathrm{L} 1+\mathrm{L} 4$ & 0 & 0 & 0 & $1(2.4)$ \\
\hline $\mathrm{L} 2+\mathrm{L} 4$ & 0 & 0 & 0 & $1(2.4)$ \\
\hline$L 3+L 4$ & 0 & 0 & 0 & $1(2.4)$ \\
\hline \multicolumn{5}{|l|}{ Site of biopsy } \\
\hline Rectum & $1(5.2)$ & 0 & 0 & $1(2.4)$ \\
\hline Rectosigmoid & 0 & 0 & 0 & $2(4.7)$ \\
\hline Sigmoid & 0 & 0 & 0 & $2(4.7)$ \\
\hline Descending colon & 0 & 0 & $1(10.0)$ & $2(4.7)$ \\
\hline Transverse colon & $3(15.7)$ & $2(25.0)$ & 0 & $4(9.5)$ \\
\hline Ascending colon & $1(5.2)$ & 1 (12.5) & $1(10.0)$ & $6(14.2)$ \\
\hline Caecum & $1(5.2)$ & 0 & $1(10.0)$ & $2(4.7)$ \\
\hline Ileocaecal & $9(47.3)$ & $2(25.0)$ & $4(40.0)$ & 8 (19.1) \\
\hline Terminal Ileum & $3(15.7)$ & $3(37.5)$ & $3(30.0)$ & 15 (35.7) \\
\hline Gastric & $1(5.2)$ & 0 & 0 & 0 \\
\hline \multicolumn{5}{|l|}{ Size of granulomas } \\
\hline Macrogranulomas (equal to diameter of 2-4 intact crypts) & $19 / 19(100)$ & 0 & NA & NA \\
\hline Microgranulomas (equal to diameter of <1 intact crypt) & $3 / 19(15.7)$ & $8 / 8(100)$ & NA & NA \\
\hline \multicolumn{5}{|l|}{ Site of granulomas } \\
\hline Mucosal & $3 / 19(15.7)$ & $8 / 8(100)$ & NA & NA \\
\hline Submucosal & 19/19 (100) & 0 & NA & NA \\
\hline
\end{tabular}


Table 1. Continued

\begin{tabular}{|c|c|c|c|c|}
\hline & \multicolumn{2}{|c|}{ Granuloma } & \multicolumn{2}{|c|}{ Non-granuloma } \\
\hline \multicolumn{5}{|c|}{ Therapeutic ATT given (post biopsy) } \\
\hline No & 0 & $5(62.5)$ & 0 & $24(57.1)$ \\
\hline Yes & $19(100)$ & $3(37.5)$ & $10(100)$ & $18(42.8)$ \\
\hline Duration of treatment (mo) & $7.7 \pm 2.0$ & $2.0 \pm 2.8$ & $9.6 \pm 5.2$ & $4.9 \pm 5.5$ \\
\hline No & $19(100)$ & $3(37.5)$ & $6(60.0)$ & $20(47.6)$ \\
\hline Yes & 0 & $5(62.5)$ & 0 & $18(42.8)$ \\
\hline Not known & 0 & 0 & $4(40.0)$ & $4(9.5)$ \\
\hline
\end{tabular}

Values are presented as mean \pm SD or number (\%).

iTB, intestinal tuberculosis; NA, not applicable; $A T$, antitubercular treatment.

Table 2. M1 (iNOS/CD68) and M2 (CD163/CD68) Macrophage Marker Scores in iTB, CD and in Controls

\begin{tabular}{|c|c|c|c|c|c|c|c|}
\hline IHC score & iTB $(n=29)$ & Control $(n=19)$ & $P$-value & $C D(n=50)$ & Control $(n=19)$ & $P$-value & $P$-value ${ }^{a}$ \\
\hline iNOS/CD68 score & & & $>0.05$ & & & $<0.05$ & $<0.05$ \\
\hline$<1$ & $20(69.0)$ & 18 (94.7) & & $23(46.0)$ & $18(94.7)$ & & \\
\hline$>2$ & $1(3.4)$ & 0 & & 0 & 0 & & \\
\hline Unstained & $2(6.9)$ & 0 & & 0 & 0 & & \\
\hline$<1$ & 3 (10.3) & $5(26.3)$ & & 12 (24.0) & $5(26.3)$ & & \\
\hline $1-2$ & $19(65.5)$ & $9(47.4)$ & & $30(60.0)$ & $9(47.4)$ & & \\
\hline$>2$ & 4 (13.8) & $4(21.1)$ & & $5(10.0)$ & $4(21.1)$ & & \\
\hline Unstained & $3(10.3)$ & $1(5.3)$ & & $3(6.0)$ & $1(5.3)$ & & \\
\hline
\end{tabular}

Values are presented as number (\%).

aiTB vs. CD.

iTB, intestinal tuberculosis; IHC, immunohistochemical.

\section{Outcome of IHC Staining}

While overall, $54.0 \%$ biopsies with CD and $20.7 \%$ biopsies with iTB showed positivity scores of 1 to 2 , only $5.3 \%$ of the control biopsies included showed similar expression of $\mathrm{Ml}_{\varphi}$ (iNOS/CD68) $(P=0.001)$. In comparison to the controls and iTB, in biopsies with $\mathrm{CD}, \mathrm{M1}_{\varphi}$ polarization was clearly in excess $(P=0.0002$ and $P=0.002$, respectively). In intestinal biopsies with iTB, $\mathrm{M} 1_{\varphi}$ marker expression was not significantly different from that of control biopsies $(P=0.2)$ (Table 2, Fig. 1). On the other hand, marker for $\mathrm{M} 2_{\varphi}(\mathrm{CD} 163 / \mathrm{CD} 68)$ did not show any significant polarity in $\mathrm{CD}$ or iTB, from that in control biopsies (Table 2, Fig. 1). Within the cases of CD included in this study, granuloma-positive CD showed $<1$ positivity score for for $\mathrm{M1}_{\varphi}$ in $87.5 \%$ cases, in comparison to only $38.1 \%$ cases of granuloma-negative CD $(P=0.02)$. Similar difference of expression was not noted with $\mathrm{M} 22_{\varphi}$ marker, between the granuloma-positive and granuloma-negative iTB $(P=0.1)$ (Table 3$)$. When all diseased biopsies were considered together, significant $\mathrm{M} 1_{\varphi}$ polarization was seen in granuloma-positive biopsies, than that in granuloma negative cases $(P=0.0001)$ (Table 3 ). Similar pattern of expression was however not seen with M2 macrophage staining. 
Table 3. M1 (iNOS/CD68) and M2 (CD163/CD68) Macrophage Polarization Pattern in iTB and CD, with and without Granulomas, as well as in Controls

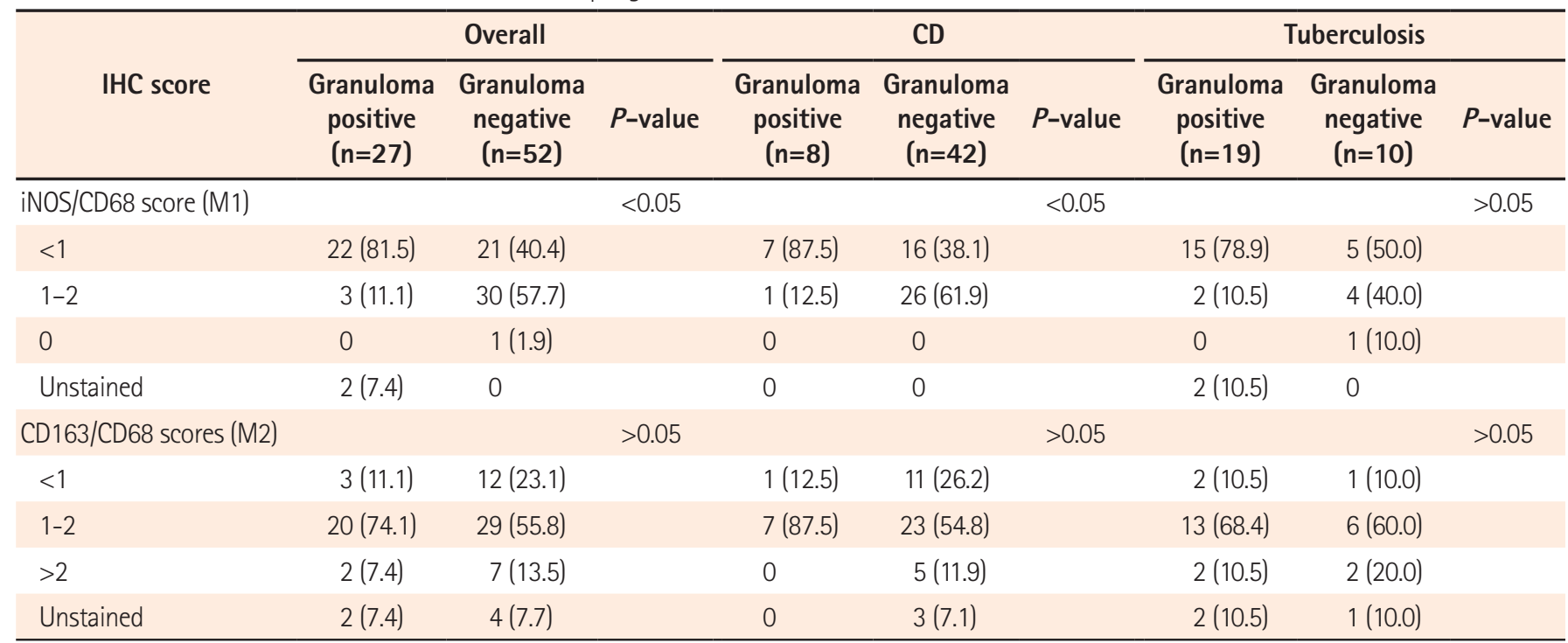

Value are presented as number (\%).

iTB, intestinal tuberculosis; IHC, immunohistochemical.
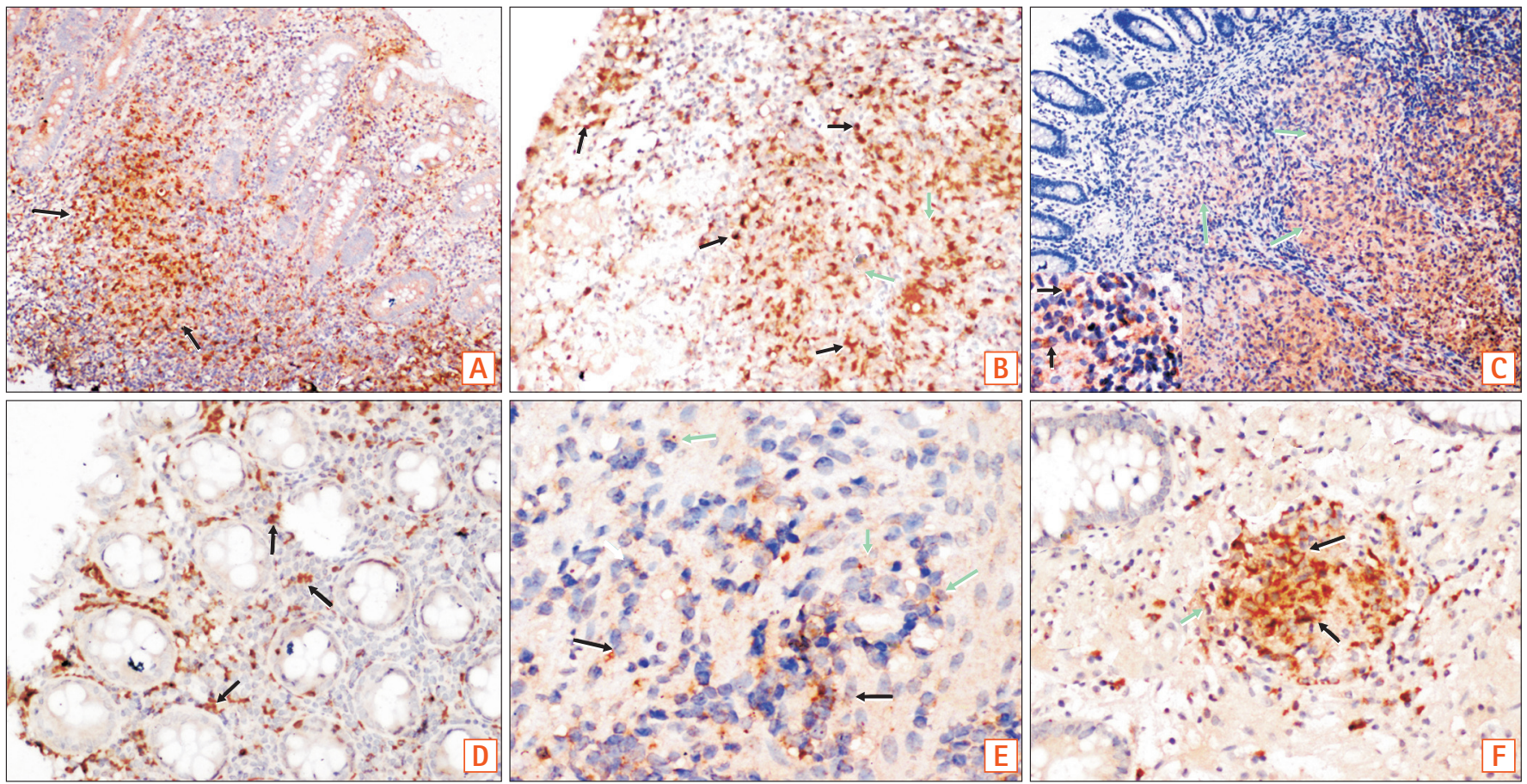

Fig. 1. (A, B) Colonic biopsies showed more proinflammatory macrophages, than the light brown CD68 positive macrophages in CD (M1 macrophages-reddish brown, black arrows \& CD68 positive macrophages, green arrows; A ×40; B ×100). (C) Figure shows confluent tubercular granulomas infiltrated by both M1 macrophages (inset, black arrows) and CD68 positive macrophages (green arrows) (×200). (D, E) Figures show iN0S/CD68 positive M1 macrophages in both superficial and deeper parts of mucosa (black arrows), as well as CD163/CD68 positive M2 macrophages (green arrows) in the deeper part of mucosa in $C D(D, \times 100 ; E, \times 400)$. (F) Figure shows polarization of $M 2$ macrophages in mucosal peri-cryptal granuloma of $C D$ (green arrow) $(\times 200)$. 


\section{Higher Inflammatory Response in Monocyte-MDM from CD Patients, as Compared to iTB upon IFN- $\gamma$ Treatment}

To check if higher $\mathrm{Ml} 1_{\varphi}$ polarization in CD biopsies was due to the inherent property of monocytes to respond aggressively against inflammatory stimuli, we compared mitochondrial depolarization in macrophages derived from PBMCs of patients having CD and iTB upon IFN- $\gamma$ treatment. PBMCs were isolated from the blood of both CD and iTB patients, and differentiated into macrophages in the presence of M-CSF. After 7 days of incubation, cells were treated with IFN- $\gamma(100 \mathrm{U} / \mathrm{mL})$ for 24 hours. We monitored mitochondrial membrane potential in control and IFN- $\gamma$ treated cells using JC-1 staining. As shown in the figure (Fig. 2), we have 6 data points from $4 \mathrm{CD}$ patients while 8 data points from 5 iTB patients. In general, we observed much more pronounced mitochondrial depolarization in MDMs isolated from CD patients, compared to those from iTB patients. While the statistical significance was at the border line, we believe a much larger comparison group would clearly distinguish the 2 groups in terms of IFN- $\gamma$ treatment.

\section{DISCUSSION}

In this study, colonic biopsies from CD, iTB and control cases were subjected to IHC staining to see differential po-

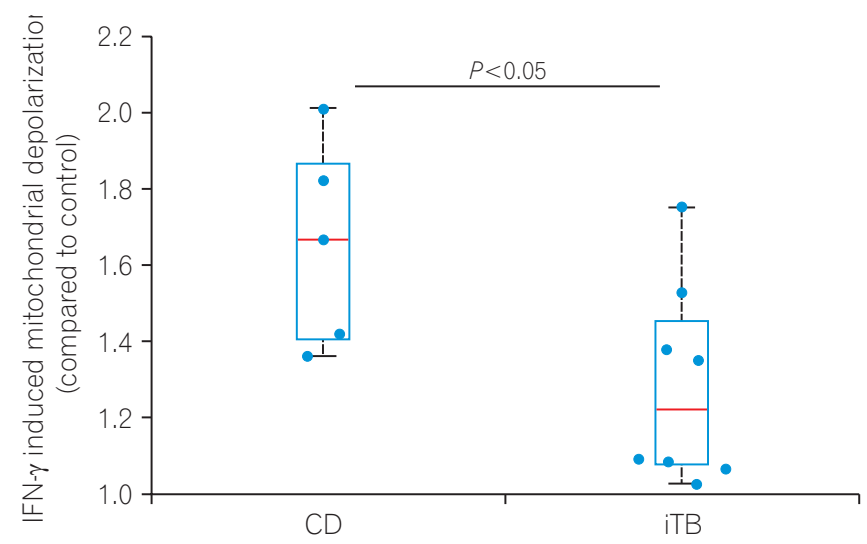

Fig. 2. Peripheral blood mononuclear cells (PBMCs) from 5 CD and 8 intestinal tuberculosis (iTB) patients were differentiated into MDM's using M-CSF (50 ng/mL, 5-7 days). Differentiated macrophages were activated by interferon $\gamma\left(\mathrm{IFN}-\gamma_{i} 100 \mathrm{U} / \mathrm{mL}, 12\right.$ hours) and stained with JC-1 dye $(2 \mu \mathrm{M})$ before analyzing the samples in a flow cytometer. The ratio of mean fluorescence intensity in the red to that of green channel is plotted here for each sample. The differences were found significant using Mann-Whitney rank test $(P<0.05)$. MDM, monocyte-derived macrophages; M-CSF, macrophage colony stimulation factors. larization pattern of $\mathrm{Ml}_{\varphi}$ and $\mathrm{M} 2_{\varphi}$, if any. We noticed proinflammatory $\mathrm{Ml}_{\varphi}$ polarity both in biopsies of $\mathrm{CD}$ and iTB, in comparison to the controls. In comparison to iTB, in CD, the $\mathrm{M} 1_{\varphi}$ polarization was more. Furthermore, in biopsies showing histological granulomas, were also found to have more $\mathrm{Ml}_{\varphi}$ polarization, in comparison to biopsies without histological evidences of granulomas. The latter pattern was especially significant in biopsies from patients with CD than in iTB. On in vitro study, the mononuclear cell derived macrophages from both $\mathrm{CD}$ and iTB patients were stimulated with IFN $-\gamma$ and macrophage membrane depolarization was assessed by JC-1 (mitochondrial membrane potential probe) dye, to validate our observation in human tissues. The in vitro results corroborated with the histopathology data as we observed heightened mitochondrial depolarization of macrophages from patients with $\mathrm{CD}$, than in iTB, upon IFN- $\gamma$ stimulation.

Though absolute specific phenotypical markers for M1 and M2 macrophages practically do not exist, various helpful markers have been identified, as CD38, Gpr18 and Fpr2 as novel M1 markers and Egr2, c-Myc as useful M2 markers. A CD38/Egr2-based flow cytometry assay is capable of distinguishing M1 and M2 macrophages efficiently, ${ }^{23}$ however, in tissues CD38 would have also expressed on differentiating B cells. Hence, in human intestinal biopsies, we chose to use iNOS for identifying the Ml macrophages, as it is highly expressed by $\mathrm{Ml}_{\varphi^{*}}$. For identifying M2 macrophages we used a combination of CD163/CD68, though there are controversies that if CD163 alone can identify M2 macrophages specifically if CD163 is a marker of macrophages as a whole. ${ }^{24}$ CD163 is a scavenger receptor and is seen on macrophages in many organs, except splenic white pulps. However, in several studies CD163 had been used as a marker of M2 macrophages. ${ }^{24,25}$ Our primary aim was to see the polarization pattern of M1 macrophages in CD, in comparison to iTB, hence, as a proof of concept study, we used these combinations. Differentiation of a macrophage-dendritic progenitor cell is dependant on the transcription factors as PU.1 and M-CSF. ${ }^{26}$ The M-CSF receptor is a tyrosine kinase transmembrane receptor, which on activation leads to receptor dimerization, autophosphorylation, PI3-kinase activation and eventually nuclear translocation of transcription factors. M-CSF mutant mice while showed reduced levels of circulating monocytes and selected macrophages; in human lack of M-CSF function leads to myelodysplastic syndrome or acute myeloid leukemia. ${ }^{19,27}$ For in vitro study, we differentiated MDMs from peripheral blood mononuclear cells, collected from both CD and iTB patients, with the help of M-CSF, and then 
examined the macrophage membrane potential with JC-1 stain, by stimulating them with IFN- $\gamma$. Using this method for measuring the macrophage membrane potential for liposomes is time tested and reliable. ${ }^{28}$

In steady state, intestinal macrophages remain in M2 state, as identified by CD206 and CD163, which produce IL-10, IL- $1 \beta$ and transforming growth factor- $\beta$ and help in proliferation of epithelial cells and proliferation of T-regulatory cells. ${ }^{26}$ Qualls and colleagues had shown that depletion of M2 macrophages in an experimental model, causes severe colitis, indicating antagonizing effects of M2 macrophages in intestinal inflammation. ${ }^{29}$ Tamoutounour and colleagues had demonstrated in a mouse model of T-cell mediated colitis that, the M1 type of pro-inflammatory macrophages become predominant after 12 hours of transfer and remain as the dominant cells till 3 weeks post-transfer. Whether the M2 macrophages, or the dendritic cells themselves can be converted into M1 type of cells during colitis is not known. ${ }^{30}$ Thiesen et al. ${ }^{31}$ had demonstrated more number of CD14 HLA-DR macrophages in inflammed colon in CD. Magnusson et al., ${ }^{32}$ also noted a similar finding. Kamada et al. ${ }^{33}$ had identified $\mathrm{CD} 14^{+} \mathrm{CD} 33^{+}$macrophages in $\mathrm{CD}$, which secreted more IL-23 and TNF- $\alpha$, on stimulation by Escherichia coli. Almost half of the colonic macrophages in CD was found to be CD14 positive. Ogino and colleagues observed CD14+ $\mathrm{CD} 163^{\text {low }}$ macrophages, which had properties similar as Th1 lymphocytes. ${ }^{34}$ Similar observations were also made in UC. Whereas in some study a M2 prominent macrophage pattern was noted in $\mathrm{UC}$, in contrast to the $\mathrm{CD},{ }^{26}$ in a study by Lissner et al., ${ }^{35}$ predominant proinflammatory $\mathrm{Ml}_{\varphi}$ reaction was noted in UC. In the latter study, in an in vitro co-culture model, the authors had demonstrated that the $\mathrm{Ml}_{\varphi}$ possibly causes apoptotic cell damage of the intestinal epithelial cells and increase trans-epithelial permeability, by altering the tight junction proteins. ${ }^{35}$ Another interesting fact is that in $\mathrm{CD}$, the tissue infiltrating macrophages may have defective function, as a result $E$. coli strain have been demonstrated within macrophages in granuloma positive CD; which is usually not the fact in UC. ${ }^{36}$ Moreover, studies on macrophage polarization in iTB is sparse, hence, our primary objective to analyze the macrophage polarization pattern between CD and iTB was novel. A literature search revealed M2 macrophage polarization in lung TB by stimulating the WNT6 signaling pathway. ${ }^{37}$ It was noted that, $M$. tuberculosis secretes virulence factors such as lipo-arabinomannan and early secretory antigenic target-6, which inhibit M1 activation ${ }^{38}$ However, in intestinal TB no such report is available.

As iNOS production is highly enhanced in Ml macro- phages, our observations on biopsy and IHC were supported by the findings of in vitro analysis. As mentioned previously, use of CD163 alone as a marker of M2 macrophages is debatable. Being a scavenger receptor, it may reflect generalized macrophage activation. However, soluble CD163 in blood, cleaved from macrophage surface by matrix mettaloproteases, also had been used as a marker of macrophage activation in literature. ${ }^{36}$ In a study by Jablonski et al., ${ }^{39}$ the authors specifically addressed this issue and tried to identify most specific marker for M1 and M2 type of macrophages by comparative transcriptional analysis, followed by flow cytometry analysis. They noted that CD38 labeled 71\% of M1 macrophages, Erg2 labeled 70\% of the M2 macrophages. However, many more markers have been described in various studies as CD38, Gpr18 and Fpr2 as novel M1 markers and Egr2, c-Myc as useful M2 markers which show relative specificity. We acknowledge therefore that a more robust panel of markers could be used to conclusively rule out any enrichment pattern of M2 macrophages. Morever, this study also needs to be expanded to a wider number of samples in future. In iTB, while $\mathrm{M} 1_{\varphi}$ polarization, was definitely less than that in CD, overall, in granuloma-positive cases, $\mathrm{Ml}_{\varphi}$ polarization was significant, possibly indicating more severe intestinal pro-inflammatory change. In granuloma-positive $\mathrm{CD}$, the clinical disease severity, number of recurrences, fistula formation, stricture, postsurgical complications are known to be more, than in the granuloma-negative CD. Looking at our observation, it appears that, due to more proinflammatory activity in intestine in granuloma-positive CD patients these complications are prevalent. This is one of the novel observations of this study. Due to the same reason, $\mathrm{CD}$, as a whole appears to be a more notorious inflammatory lesion of intestine, than that of iTB, especially, in terms of chronicity and response to treatment concerned. We again highlight the fact that, while the $\mathrm{Ml}_{\varphi}$ was significantly more in granuloma-positive $\mathrm{CD}$ than the granuloma-negative $\mathrm{CD}$, between granuloma-positive and negative iTB, similar difference was not seen. However, it is needed to be highlighted that, M2 macrophage numbers are also increased in both $\mathrm{CD}$ and $\mathrm{iTB}$, than the controls (though not statistically significant). Classically M2 macrophages are considered necessary for development of fibrosis and wound healing. M2 macrophages, have also been shown to reduce the overall local intestinal immunity, leading to development of disease recurrence and opportunistic infections. ${ }^{35.36}$

Hence, this study provides a preliminary insight on the fact that, $\mathrm{Ml}_{\varphi}$ are significantly polarized in intestinal mucosa of $\mathrm{CD}$, then in iTB. $\mathrm{Ml}_{\varphi}$ polarization is further prominent 
in chronic intestinal inflammation with presence of granulomas. Since MDMs from CD showed heightened inflammatory response than those from iTB upon encountering inflammatory stimuli, the study also, albeit preliminarily, suggest inherent innate defense mechanism as the possible key player in the pathology of CD. This knowledge, not only enriches us regarding complex pathogenesis of intestinal inflammatory conditions, but also shows hope in using $\mathrm{Ml}_{\varphi}$ targeted therapeutic agents in near future. Presence of more pro-inflammatory $\mathrm{Ml}_{\varphi}$ in intestinal wall in granuloma-positive CD might explain the disease severity, recurrent, fistula, postsurgery complications already reported in this subset of CD.

\section{FINANCIAL SUPPORT}

This work was supported by the research grant of the Science \& Engineering Research Board, affiliated to the Department of Science and Technology, Government of India (grant ID: EMR/2016/005296).

\section{CONFLICT OF INTEREST}

No potential conflict of interest relevant to this article was reported.

\section{AUTHOR CONTRIBUTION}

P.D., R.R., T.K., S.P., S.K., S.D.G., D.K., V.A. were actively involved in planning and execution of this study and writing this manuscript. S.U. \& D.K. were responsible for in-vitro confirmation of M1 macrophage polarization from PBMCs. N.W. \& I.K.A. were responsible for organizing the patient's samples and in laboratory analyses. P.D., S.K., S.D.G., D.K. \& V.A. were also involved in critical analyses of the manuscript. V.A. is the overall guarantor of this article.

\section{REFERENCES}

1. Makharia GK, Srivastava S, Das P, et al. Clinical, endoscopic, and histological differentiations between Crohn's disease and intestinal tuberculosis. Am J Gastroenterol 2010;105:642-651.

2. Ahuja V, Tandon RK. Inflammatory bowel disease: the Indian augury. Indian J Gastroenterol 2012;31:294-296.

3. Pratap Mouli V, Munot K, Ananthakrishnan A, et al. Endoscopic and clinical responses to anti-tubercular therapy can differentiate intestinal tuberculosis from Crohn's disease. Aliment Pharmacol Ther 2017;45:27-36.
4. Turner K, Genta RM, Lujan G, Robiou C, Sonnenberg A. Significance of the epithelioid granuloma in biopsies of Crohn's colitis. Inflamm Bowel Dis 2014;20:2271-2275.

5. Freeman HJ. Granuloma-positive Crohn's disease. Can J Gastroenterol 2007;21:583-587.

6. Neurath MF, Finotto S, Glimcher LH. The role of Th1/Th2 polarization in mucosal immunity. Nat Med 2002;8:567-573.

7. Maloy KJ, Powrie F. Regulatory T cells in the control of immune pathology. Nat Immunol 2001;2:816-822.

8. de Jong YP, Abadia-Molina AC, Satoskar AR, et al. Development of chronic colitis is dependent on the cytokine MIF. Nat Immunol 2001;2:1061-1066

9. Koboziev I, Karlsson F, Grisham MB. Gut-associated lymphoid tissue, T cell trafficking, and chronic intestinal inflammation. Ann N Y Acad Sci 2010;1207 Suppl 1:E86-E93. doi: 10.1111/ j.1749-6632.2010.05711.x.

10. Moser M, Murphy KM. Dendritic cell regulation of TH1-TH2 development. Nat Immunol 2000;1:199-205.

11. Blumberg RS, Saubermann LJ, Strober W. Animal models of mucosal inflammation and their relation to human inflammatory bowel disease. Curr Opin Immunol 1999;11:648-656.

12. Martinez FO, Gordon S. The M1 and M2 paradigm of macrophage activation: time for reassessment. F1000Prime Rep 2014;6:13. doi: 10.12703/P6-13.

13. Mackaness GB. Cellular resistance to infection. J Exp Med 1962;116:381-406.

14. Stein M, Keshav S, Harris N, Gordon S. Interleukin 4 potently enhances murine macrophage mannose receptor activity: a marker of alternative immunologic macrophage activation. J Exp Med 1992;176:287-292.

15. Doyle AG, Herbein G, Montaner LJ, et al. Interleukin-13 alters the activation state of murine macrophages in vitro: comparison with interleukin-4 and interferon-gamma. Eur J Immunol 1994;24:1441-1445.

16. Mills CD, Kincaid K, Alt JM, Heilman MJ, Hill AM. M-1/ M-2 macrophages and the Th1/Th2 paradigm. J Immunol 2000;164:6166-6173.

17. Mantovani A, Sica A, Sozzani S, Allavena P, Vecchi A, Locati M. The chemokine system in diverse forms of macrophage activation and polarization. Trends Immunol 2004;25:677-686.

18. Hansen G, Hercus TR, McClure BJ, et al. The structure of the GM-CSF receptor complex reveals a distinct mode of cytokine receptor activation. Cell 2008;134:496-507.

19. Lacey DC, Achuthan A, Fleetwood AJ, et al. Defining GM-CSFand macrophage-CSF-dependent macrophage responses by in vitro models. J Immunol 2012;188:5752-5765. 
20. Matta SK, Kumar D. Hypoxia and classical activation limits Mycobacterium tuberculosis survival by Akt-dependent glycolytic shift in macrophages. Cell Death Discov 2016;2:16022. doi: 10.1038/cddiscovery.2016.22.

21. Stange EF, Travis SP, Vermeire S, et al. European evidence based consensus on the diagnosis and management of Crohn's disease: definitions and diagnosis. Gut 2006;55 Suppl 1:i1-i15.

22. Paustian F. Tuberculosis of the intestine. In: Bockus HL, Schaffner F, Berk JE eds. Bockus gastroenterology. 5th ed. Philadelphia: Saunders, 1995:3304.

23. Barros MH, Hauck F, Dreyer JH, Kempkes B, Niedobitek G. Macrophage polarisation: an immunohistochemical approach for identifying M1 and M2 macrophages. PLoS One 2013;8:e80908. doi: 10.1371/journal.pone.0080908.

24. Buechler C, Ritter M, Orsó E, Langmann T, Klucken J, Schmitz G. Regulation of scavenger receptor CD163 expression in human monocytes and macrophages by pro- and antiinflammatory stimuli. J Leukoc Biol 2000;67:97-103.

25. Sulahian TH, Högger P, Wahner AE, et al. Human monocytes express CD163, which is upregulated by IL-10 and identical to p155. Cytokine 2000;12:1312-1321.

26. Isidro RA, Appleyard CB. Colonic macrophage polarization in homeostasis, inflammation, and cancer. Am J Physiol Gastrointest Liver Physiol 2016;311:G59-G73.

27. Tobal K, Pagliuca A, Bhatt B, Bailey N, Layton DM, Mufti GJ. Mutation of the human FMS gene (M-CSF receptor) in myelodysplastic syndromes and acute myeloid leukemia. Leukemia 1990;4:486-489.

28. Cossarizza A, Baccarani-Contri M, Kalashnikova G, Franceschi C. A new method for the cytofluorimetric analysis of mitochondrial membrane potential using the J-aggregate forming lipophilic cation 5,5,6,6'-tetrachloro-1,1'3,3'-tetraethylbenzimidazolcarbocyanine iodide (JC-1). Biochem Biophys Res Commun 1993;197:40-45.

29. Qualls JE, Kaplan AM, van Rooijen N, Cohen DA. Suppression of experimental colitis by intestinal mononuclear phagocytes. J Leukoc Biol 2006;80:802-815.
30. Tamoutounour S, Henri S, Lelouard H, et al. CD64 distinguishes macrophages from dendritic cells in the gut and reveals the Th1-inducing role of mesenteric lymph node macrophages during colitis. Eur J Immunol 2012;42:3150-3166.

31. Thiesen S, Janciauskiene S, Uronen-Hansson H, et al. CD14(hi) HLA-DR(dim) macrophages, with a resemblance to classical blood monocytes, dominate inflamed mucosa in Crohn's disease. J Leukoc Biol 2014;95:531-541.

32. Magnusson MK, Brynjólfsson SF, Dige A, et al. Macrophage and dendritic cell subsets in IBD: ALDH+ cells are reduced in colon tissue of patients with ulcerative colitis regardless of inflammation. Mucosal Immunol 2016;9:171-182.

33. Kamada N, Hisamatsu T, Okamoto S, et al. Unique CD14 intestinal macrophages contribute to the pathogenesis of Crohn disease via IL-23/IFN-gamma axis. J Clin Invest 2008;118:22692280.

34. Ogino T, Nishimura J, Barman S, et al. Increased Th17-inducing activity of CD14+ CD163 low myeloid cells in intestinal lamina propria of patients with Crohn's disease. Gastroenterology 2013;145:1380-1391.e1.

35. Lissner D, Schumann M, Batra A, et al. Monocyte and M1 macrophage-induced barrier defect contributes to chronic intestinal inflammation in IBD. Inflamm Bowel Dis 2015;21:12971305 .

36. Kühl AA, Erben U, Kredel LI, Siegmund B. Diversity of intestinal macrophages in inflammatory bowel diseases. Front Immunol 2015;6:613. doi: 10.3389/fimmu.2015.00613.

37. Schaale K, Brandenburg J, Kispert A, Leitges M, Ehlers S, Reiling $\mathrm{N}$. Wnt6 is expressed in granulomatous lesions of Mycobacterium tuberculosis-infected mice and is involved in macrophage differentiation and proliferation. J Immunol 2013;191:51825195 .

38. Lugo-Villarino G, Vérollet C, Maridonneau-Parini I, Neyrolles O. Macrophage polarization: convergence point targeted by mycobacterium tuberculosis and HIV. Front Immunol 2011;2:43. doi: 10.3389/fimmu.2011.00043.

39. Jablonski KA, Amici SA, Webb LM, et al. Novel markers to delineate murine M1 and M2 macrophages. PLoS One 2015;10:e0145342. doi: 10.1371/journal.pone.0145342. 